\title{
Interpretive bias in social phobia: An ERP study with morphed emotional schematic faces
}

\author{
Iris-Tatjana Kolassa \\ Friedrich Schiller University of Jena, Jena, and University of Konstanz, \\ Konstanz, Germany \\ Stephan Kolassa, Sandra Bergmann, Romy Lauche, \\ Stefan Dilger, Wolfgang H. R. Miltner, and Frauke Musial \\ Friedrich Schiller University of Jena, Jena, Germany
}

Individuals with social phobia fear negative evaluation, which is most directly signalled by an angry expression of the interlocutor's face. This study investigated the processing of 3 series of schematic emotional faces, which were morphed in 7 steps from a neutral face to an angry, happy, or sad face by systematically varying features of the mouth, eyes, and eyebrows. Individuals with social phobia or spider phobia rated angry faces as more arousing than controls. Social phobics did not identify angry faces faster and showed no greater latent trait to identify a face as angry than controls. ERP data showed a modulation of the face-specific N170 by facial emotion, although this did not discriminate social phobics from controls. Instead, phobic subjects exhibited generally increased visual P1 amplitudes, suggesting a state of hypervigilance for incoming stimuli. Results are discussed in the context of psychophysiological abnormalities in the anxiety disorder spectrum.

Correspondence should be addressed to: Iris-Tatjana Kolassa, Department of Psychology, Clinical Psychology, PO Box 5560, D25, University of Konstanz, D-78457 Konstanz, Germany. E-mail: Iris.Kolassa@uni-konstanz.de

This study was funded by grant Mi265/6-1/6-2 of the German Research Foundation (Deutsche Forschungsgemeinschaft) awarded to WHRM. We would also like to thank the German National Academic Foundation (Studienstiftung des deutschen Volkes) for awarding a doctoral grant to ITK.

ITK is now at the Department of Psychology, Clinical Psychology, University of Konstanz, Germany. SB is now at the Institut für Therapieforschung, Munich, Germany. SK is now at SAF AG, Tägerwilen, Switzerland. FM is now at the University of Duisburg-Essen, Complementary and Integrative Medicine, Essen.

Thanks are also due to Arlette Buchmann for her assistance in conducting the study. 
The core symptom of social phobia is fear of embarrassment, humiliation, and negative evaluation in social interaction and performance situations. Social approval or disapproval during interactions with others is most directly signalled by facial expressions. In particular, an angry face directly signals the violation of social rules or social expectations (compare Averill, 1982) - a situation that persons with social phobia fear.

Several studies found evidence for abnormal processing of emotional faces, in particular angry faces, in social phobia: Lundh and Öst (1996) as well as Coles and Heimberg (2005) reported a recognition bias for critical compared to accepting faces in social phobia. Furthermore, an attentional bias for socially threatening words (Becker, Rinck, Margraf, \& Roth, 2001; Hope, Rapee, Heimberg, \& Dombeck, 1990; Lundh \& Öst, 1996; Maidenberg, Chen, Craske, Bohn, \& Bystritsky, 1996; Mattia, Heimberg, \& Hope, 1993; Spector, Pecknold, \& Libman, 2003) and faces (Mansell, Ehlers, Clark, \& Chen, 2002; Pishyar, Harris, \& Menzies, 2004) has been observed. In a visual search paradigm, a so-called "face-in-the-crowd paradigm", persons with generalised social phobia and non-anxious controls both detected angry faces faster than happy ones in a neutral crowd, but individuals with social phobia showed an even faster response than controls (GilboaSchechtman, Foa, \& Amir, 1999).

Functional MRI studies showed enhanced amygdala activation in response to angry (Phan, Fitzgerald, Nathan, \& Tancer, 2006; Stein, Goldin, Sareen, Zorrilla, \& Brown, 2002; Straube, Kolassa, Glauer, Mentzel, \& Miltner, 2004) or even neutral faces (Birbaumer et al., 1998; Veit et al., 2002) in individuals with social phobia. In a recent fMRI study, Straube, Mentzel, and Miltner (2005) observed that social phobics not only showed greater amygdala activity in response to angry faces compared to controls, but that they exhibited generally enhanced amygdala activity in response to emotional (angry and happy) faces. This finding supports the role of the amygdala in the processing of potential threats and the initiation of fear responses (LeDoux, 1998). Furthermore, Straube et al. found increased activation of extrastriate visual cortex regardless of facial expression, suggesting a state of alertness or hypervigilance in the visual cortex that might possibly be triggered by re-entrant projections from the amygdala to the visual system that enhance attention and perceptual processing of motivationally relevant events (Amaral, Price, Pitkanen, \& Carmichael, 1992).

Whereas several studies investigated the processing of emotional and in particular angry faces in social phobia using fMRI, to our knowledge only a few studies used event-related potentials (ERPs) to investigate abnormal face processing in social phobia (Kolassa, Kolassa, Musial, \& Miltner, 2007; Kolassa \& Miltner, 2006). The N170 is known to be a face-specific ERP component (Bentin, Allison, Puce, Perez, \& McCarthy, 1996; however, see 
Kolassa, Musial, Kolassa, \& Miltner, 2006), presumably originating from posterior lateral temporal brain areas, possibly in the inferior temporal gyrus (compare also Henson et al., 2003; Schweinberger, Pickering, Jentzsch, Burton, \& Kaufmann, 2002). Recently, evidence has accumulated that the N170 amplitude is modulated by facial emotion if the emotion of the depicted face is task relevant (Batty \& Taylor, 2003; Blau, Maurer, Tottenham, \& McCandliss, 2007; Caharel, Courtay, Bernard, Lalonde, \& Rebai, 2005; Kolassa \& Miltner, 2006; Pizzagalli, Lehmann, Koenig, Regard, \& Pascual-Marqui, 2000). Furthermore, it has been shown that social phobic individuals show enhanced right temporo-parietal N170 amplitudes to angry faces if the emotional content of the face stimulus is the explicit focus of attention (Kolassa \& Miltner, 2006). However, when using schematic instead of photographic faces no such effect was observed (Kolassa et al., 2007).

The P1 is known to be attention sensitive (see Luck, Woodman, \& Vogel, 2000; Mangun, 1995, for reviews), and measures early attention allocation in the extrastriate visual cortex. Smith, Cacioppo, Larsen, and Chartrand (2003) showed that the brain differentiates positive and negative stimuli extremely rapidly $(<120 \mathrm{~ms})$ and that this differentiation is reflected in the modulation of P1 amplitude: larger P1 amplitudes to frequent and to rare negative stimuli compared to rare positive stimuli were observed.

Furthermore, P1 has been shown to be modulated by personal affective judgement of faces as liked or disliked (Pizzagalli, Regard, \& Lehmann, 1999). Images of fearful faces, relative to neutral faces, elicit a higher global field power approximately $130 \mathrm{~ms}$ after stimulus onset, corresponding to an increased P1 component over lateral occipital electrodes, with neural sources located within the extrastriate visual cortex (Pourtois, Dan, Grandjean, Sander, \& Vuilleumier, 2005a). Moreover, the presentation of fear cues such as fearful faces relative to neutral faces seems to facilitate the sensory processing of stimuli occurring in the same location (Pourtois, Grandjean, Sander, \& Vuilleumier, 2004). This sensory facilitation was reflected in enhanced lateral occipital P1 amplitudes when a bar, which had to be judged regarding its orientation, replaced a fearful compared to a neutral face (Pourtois et al., 2004; Pourtois, Thut, Grave de Peralta, Michel, \& Vuilleumier, 2005b).

In an experiment using schematic face stimuli, Kolassa et al. (2007) observed generally enhanced P1 amplitudes in social phobic persons compared to non-phobic controls in response to angry, happy and neutral schematic faces, which is consistent with the findings of increased extrastriate visual cortex activation in social phobics when viewing pictures of faces (Straube et al., 2005).

This study was an extension of the study by Kolassa et al. (2007), which investigated the processing of schematic faces in social phobia. The present study aimed at investigating a possible interpretation bias in social phobia by 
using schematic faces with varying degrees of ambiguity. This interpretation bias should be expressed as differences in latent classification traits and reaction times between social phobic and control participants. In addition, we sought to elucidate the electrophysiological correlates of such an interpretation bias. Three series of schematic face stimuli were used, which-starting from the picture of a neutral face-were morphed into increasingly pronounced angry, happy, or sad faces by systematically varying the shape of the mouth, the shape of the eyes, and the angle of the eyebrows. The advantages of schematic stimuli are that they reduce the depicted object to its essential components. Schematic stimuli show less variance: in the case of facial stimuli there is no confounding of ethnicity, gender, familiarity of faces, or sympathy effects. Furthermore, it is possible to design different emotional faces consisting of visual elements that are as similar as possible, avoiding differences in spatial frequency. The schematic faces used were prototypic line drawings of facial expressions, which provide enough information for the recognition of emotional expression (Öhman, Lundqvist, \& Esteves, 2001). It has been shown in previous studies that schematic threatening faces are detected faster than non-threatening faces in nonphobic control persons (Öhman et al., 2001; Schubö, Gendolla, Meinecke, \& Abele, 2006) and that this detection advantage is not present for key features of threatening faces when presented outside the perceptual gestalt of a face (Schubö et al., 2006). Furthermore, in studies with social phobic individuals, such simplified threatening face stimuli elicited differential brain responses in social phobics relative to healthy control subjects (Straube et al., 2004).

Several studies have shown that individuals with social phobia are more likely to misinterpret ambiguous social situations as more threatening and to draw more negative inferences from available social stimuli than controls (Amir, Foa, \& Coles, 1998a, 1998b; Stopa \& Clark, 2000). Indeed, during ambiguous social situations, non-anxious individuals are characterised by a benign on-line inferential bias, i.e., when ambiguous information about social situations is first encountered they draw positively biased inferences; however, people with social phobia showed no evidence of making on-line emotional inferences, leading to the conclusion that the benign on-line inferential bias is impaired in people with social phobia (Hirsch \& Mathews, 2000). To our knowledge, a similar (negative) interpretation bias for facial stimuli has not been investigated so far. The present study thus became the first to investigate the processing of morphed schematic faces in (a) nonphobic control persons and (b) social phobic individuals.

We expected social phobics to classify faces more easily as angry than the other groups. We were also interested in corresponding response latencies and the N170 and P1 amplitudes of facial ERPs. We hypothesised that social phobics would identify angry faces faster than happy, neutral, or sad faces. Furthermore, we expected increased P1 amplitudes in individuals with social 
phobia in response to faces in general and increased N170 amplitudes in response to angry faces in particular.

\section{METHODS}

\section{Subjects}

Forty-five subjects, age range $19-34$ years $(M=23.02$ years, $S D=3.57)$, were recruited from the university student community by announcements on public boards, in lectures, and newspaper advertisements. Forty-three subjects were right-handed and two left-handed as measured by the Edinburgh handedness inventory (Oldfield, 1971). Three groups were investigated: 15 individuals with social phobia ( 8 female, 7 male), 15 individuals with spider phobia (7 female, 8 male) as an additional phobic control group, and 15 non-phobic control subjects (8 female, 7 male). All participants provided informed consent and the experimental procedures were approved by the ethics committee of the University of Jena. Subjects were paid $€ 6$ per hour for participation. Additionally, social phobic patients were offered a 10-session social skills group training (Hinsch \& Pfingsten, 2002), and spider phobic individuals could participate in a one-day spider phobia treatment (Öst, 1989).

In a preliminary interview, all subjects were screened with the Structured Clinical Interview for DSM-IV (SCID-I; Wittchen, Wunderlich, Gruschwitz, \& Zaudig, 1997). Social phobic participants fulfilled DSM-IV (American Psychiatric Association, 1994) criteria for social phobia, and participants with spider phobia met DSM-IV criteria for specific (animal) phobia. Phobic participants had no current symptoms or history of other major axisI disorders. Non-phobic controls also had no current or known history of major disorders according to DSM-IV. Subjects completed the Social Phobia and Anxiety Inventory (SPAI; Fydrich, 2002; Turner, Beidel, Dancu, \& Stanley, 1989) the Spider Questionnaire (SPQ; Klorman, Weerts, Hastings, Melamed, \& Lang, 1974), the Beck Depression Inventory (BDI; Hautzinger, Bailer, Worall, \& Keller, 2000), the State Trait Anxiety Inventory (STAI; Laux, Glanzmann, Schaffner, \& Spielberger, 1981), and the Fear Survey Schedule (FSS; Wolpe \& Lang, 1964), which covers the range of the most common sources of anxiety. See Table 1 for mean questionnaire values and standard deviations.

\section{Stimuli}

Three series of schematic faces were designed (see Figure 1), which - starting from the picture of a neutral face-were morphed into more and more intensely angry, happy, or sad faces by systematically varying the shape of 
TABLE 1

Mean questionnaire values $(M)$ and standard deviations $(S D)$ for each group

\begin{tabular}{|c|c|c|c|c|c|c|c|}
\hline \multirow[b]{2}{*}{ Questionnaire } & \multicolumn{2}{|c|}{ Control group } & \multicolumn{2}{|c|}{ Social phobics } & \multicolumn{2}{|c|}{ Spider phobics } & \multirow[b]{2}{*}{ One-way ANOVA } \\
\hline & $M$ & $S D$ & $M$ & $S D$ & $M$ & $S D$ & \\
\hline SPAI & 34.67 & 16.45 & 128.80 & 16.46 & 46.28 & 13.91 & $F(2,42)=161.19, p<.0001$ * \\
\hline SPQ & 2.07 & 1.58 & 2.73 & 1.94 & 20.47 & 2.70 & $F(2,42)=361.89, p<.0001^{\dagger+}$ \\
\hline BDI & 2.67 & 3.04 & 8.60 & 4.67 & 4.93 & 4.06 & $F(2,42)=8.48, p<.001^{* \sharp}$ \\
\hline STAI-T & 29.87 & 6.19 & 50.80 & 6.33 & 33.80 & 8.73 & $F(2,42)=36.06, p<.0001^{* \star}$ \\
\hline FSS & 20.36 & 33.24 & 77.53 & 31.92 & 46.13 & 23.89 & $F(2,42)=20.60, p<.0001 * \hbar$ \\
\hline
\end{tabular}

Notes: The German scores of the Social Phobia and Anxiety Inventory (SPAI) were transformed into the original scores (Turner et al., 1989). STAI-T = State-Trait Anxiety Inventory-Trait Version; $\mathrm{BDI}=$ Beck Depression Inventory; SPQ $=$ Spider Questionnaire. Tukey HSD post hoc tests: *Control group differs from social phobics $(p<.001)$. ${ }^{\dagger}$ Control group differs from spider phobics $(p<.02)$. ${ }^{\ddagger}$ Social phobics differ from spider phobics $(p<.05)$.

\section{Emotional Faces}

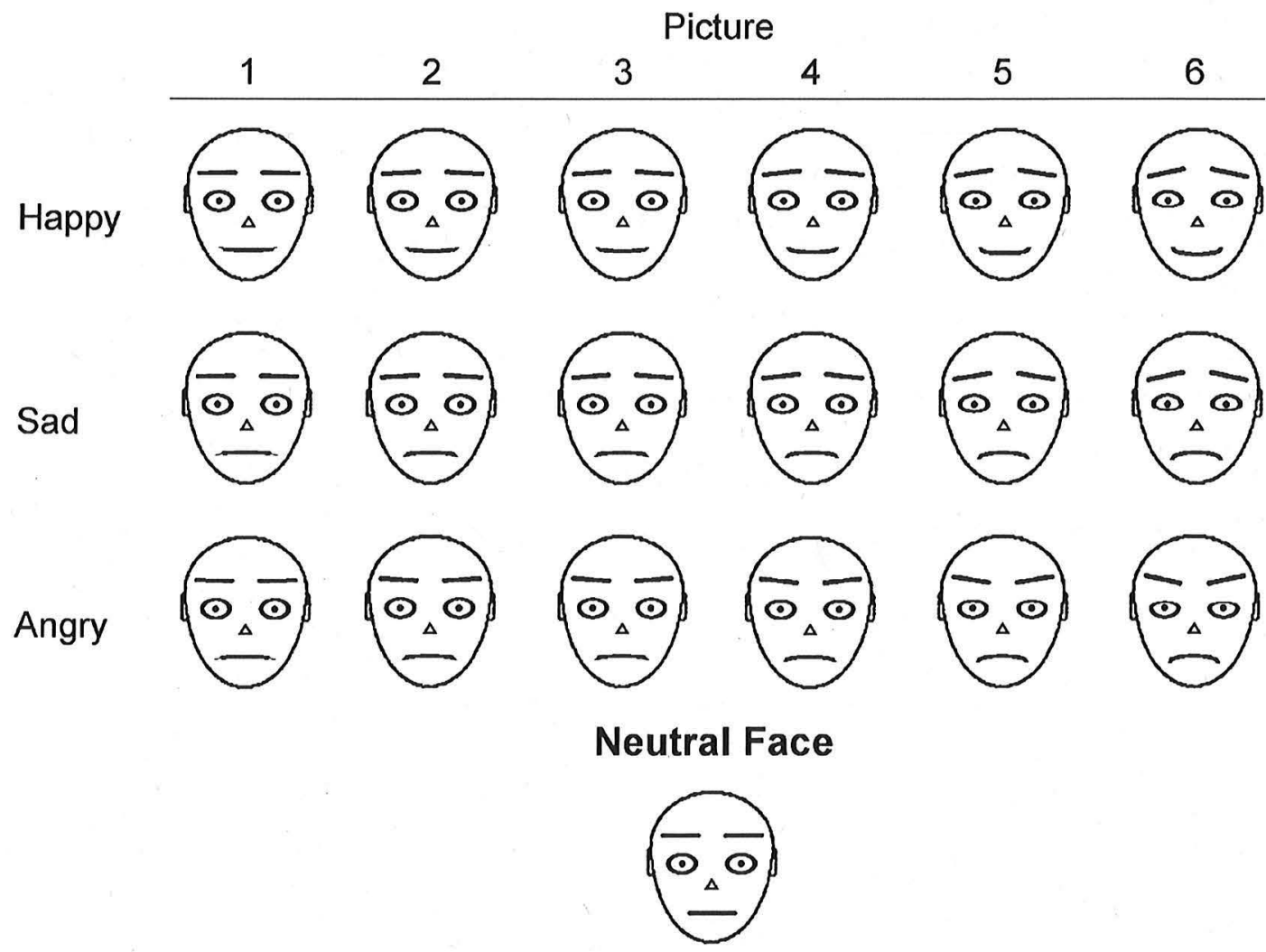

Figure 1. Three series of schematic face stimuli: Beginning with a neutral face the facial emotion of the three picture series (neutral-angry, neutral-happy, neutral-sad) was gradually enhanced by varying systematically the shape of the mouth, the shape of the eyes and the angle of the eyebrows. 
the mouth, the shape of the eyes, and the angle of the eyebrows across a series of 6 pictures. The schematic faces were designed following Lundqvist, Esteves, and Öhman (1999) and Öhman et al. (2001). Stimuli were about $16 \mathrm{~cm}$ in height and $19 \mathrm{~cm}$ in width.

\section{Procedure and paradigm}

During the testing session, subjects sat in a comfortable chair in a soundattenuated and electrically shielded room. Stimuli were presented on a 20 inch Sony monitor (resolution $800 \times 600$ ) with the software ERTS (Experimental Runtime System, Version 3.18, BeriSoft, Germany). The distance between the computer monitor and participant's eyes was about $1.1 \mathrm{~m}$.

Before the actual experiment started, each picture was rated on affective valence and arousal with an adapted version of the Self-Assessment Manikin scale (SAM; Bradley \& Lang, 1994; Lang, 1980). The SAM is a relatively culture-free pictographic assessment instrument, which has been used in various emotion studies. Subjects sat in front of the stimulation computer screen with a paper version of the SAM rating scale lying in front of them. Facial stimuli were presented in pseudorandomised order on the screen for $10 \mathrm{~s}$ followed by a $12 \mathrm{~s}$ inter-stimulus interval. There were three different pseudorandomised versions of stimulus order, which were randomised across subjects. The subject was instructed to speak aloud the valence and arousal rating for each stimulus, which was then recorded by the experiment supervisor.

During the actual experiment, stimuli were presented multiple times, both in random and in ascending/descending order. The sequence of orders was randomised across subjects. Because results of both orders were very similar, only the data of the randomised design will be presented here. Each one of the 6 stimuli of the 3 schematic emotional face series as well as the single neutral face was presented 15 times, which makes a total of $6 \times 3 \times 15+1 \times$ $15=285$ trials. Identical facial stimuli were never presented twice in a row. Each stimulus was presented for $3 \mathrm{~s}$, during which the subject pressed one of four buttons to classify the face as either happy, angry, sad, or neutral as quickly as possible. Because this paradigm measures a person's subjective judgement, there is no right or wrong answer in a trial. However, we wanted to exclude trials on which subjects had mistakenly pressed the wrong key. Therefore, after each trial the question "Correct/Incorrect?" appeared for $2 \mathrm{~s}$ (plus an exponential distribution with mean $0.5 \mathrm{~s}$, truncated at $1 \mathrm{~s}$ as realised by ERTS, Experimental Runtime System, version 3.18, BeriSoft, Germany) on the screen and subjects had to indicate, again via a key press, whether their choice had been correct or whether they had pressed a wrong button by mistake. Pressing either of the two keys on the left indicated that their response was correct; pressing either of the two keys on the right indicated 
that it was incorrect. Before the actual experiment started, participants performed a training task, which they could repeat as often as they judged necessary.

\section{Assessment and analysis of EEG}

EEG was recorded using $62 \mathrm{Ag} / \mathrm{AgCl}$ electrodes mounted in an Easy-Cap (Falk Minow Services, Germany) according to the international 10-10 system (Chatrian, Lettich, \& Nelson, 1988) with additional non-standard electrodes (AF1, AF2, PO1, PO3) at frontal and occipital sites spaced equally between the standard electrodes. $\mathrm{Cz}$ served as the reference electrode, and a ground electrode was placed at the forehead. All electrode impedances were kept below $5 \mathrm{k} \Omega$. Vertical and horizontal electro-oculograms (VEOG and HEOG) were recorded for off-line correction of eye movements and blink artefacts. Synamp amplifiers (Neuroscan) were used for EEG and EOG acquisition. All signals were sampled continuously in AC-mode at a rate of $500 \mathrm{~Hz}$ (gain $=1000$, low pass filter $=70 \mathrm{~Hz}$, high pass filter $=$ $0.05 \mathrm{~Hz}$ ). Data acquisition was performed with Acquire 4.1.1 (Neurosoft).

Offline, EEG raw data were filtered (low pass $=30 \mathrm{~Hz}, 24 \mathrm{~dB} /$ oct, high pass $=0.1 \mathrm{~Hz}, 24 \mathrm{~dB} /$ oct, $50 \mathrm{~Hz}$ Notch), segmented (200 ms pre- to $1300 \mathrm{~ms}$ post-stimulus), corrected for blinks and eye movements (Gratton, Coles, \& Donchin, 1983), and screened for artefacts using Brain Vision Analyzer 1.04 (Brain Products $\mathrm{GmbH}$, Germany). Trials containing artefacts (minimal allowed amplitude $-150 \mu \mathrm{V}$, maximal allowed amplitude $150 \mu \mathrm{V}$, maximum voltage difference between neighbouring sampling points $50 \mu \mathrm{V}$, maximal allowed absolute difference of two values in a segment $150 \mu \mathrm{V}$ ) or those that subjects had indicated as being wrong responses were rejected. Altogether, $11.8 \%$ of total trials were excluded. Artefact-free EEG epochs were averaged depending on subjects' categorisation of faces as angry, happy, sad, or neutral (response-dependent analysis). Grand means are based on the following number of trials: 2193 faces classified as angry, 2849 as happy, 3524 as sad, and 1995 as neutral.

All epochs were aligned to the $200 \mathrm{~ms}$ pre-stimulus baseline and then rereferenced to an average reference. Data of 3 subjects (1 control, 1 social phobic, 1 spider phobic) had to be excluded due to severe occipito-parietal alpha activity. Grand averages were calculated for each individual and each condition and peaks were detected semi-automatically within certain time intervals. N170 peaks were detected at leads P7 and P8 within the time interval 120-200 ms; P1 and P2 amplitudes were detected at electrodes O1, $\mathrm{Oz}$, and $\mathrm{O} 2$ within the time intervals $50-120 \mathrm{~ms}$ (P1) and 170-250 ms (P2), respectively. Subsequent visual inspection ensured that peaks were detected correctly. 


\section{Statistical analysis}

For data analysis, linear mixed effects models (Laird \& Ware, 1982) were implemented using SAS 9.1 (SAS Institute, Inc.). In all analyses of variance (ANOVAs) and analyses of covariance (ANCOVAs), Subjects served as a random effect, whereas all other factors were fixed effects. Linear mixed models are particularly well suited for repeated measurement designs within the same individual that can lead to positive correlations between measurements. Significant effects in an ANOVA were further analysed by calculating contrasts, where rejection of the null hypothesis was controlled by Holm's sequential rejection algorithm (Holm, 1979). Original $p$-values that remained significant after $\alpha$-correction are reported below.

Valence and arousal ratings were analysed by an ANCOVA with betweenfactor Group and repeated-measures factors Emotion (angry, happy, sad) and Picture (Pictures 1 to 6). Valence and arousal ratings of neutral faces were used as covariates in the respective ANCOVAs. The criteria of homogeneity of slopes and common covariate group means were fulfilled.

For the analysis of stimulus classifications, a modified mixed Rasch model was used for each stimulus series. The probability that a subject would classify a stimulus as a certain emotion was modelled as $\exp (\mathrm{z}) /(1+\exp (\mathrm{z}))$, where $\mathrm{z}=\alpha_{\mathrm{So}} \mathrm{x}_{\mathrm{So}}+\alpha_{\mathrm{Sp}} \mathrm{x}_{\mathrm{Sp}}-\Sigma_{\mathrm{i}} \delta_{\mathrm{i}} \mathrm{x}_{\mathrm{i}}+\theta$. In this formula, $\alpha$ denotes the groups' latent traits with the control group's trait set to $0, \delta_{\mathrm{i}}$ the ith stimulus item difficulty, $\theta$ a normally distributed error term with mean 0 and all $\mathrm{x}$ indicator variables. Trials in which the subject indicated that the answer was wrong were excluded from analysis, and model parameters were fitted with the nonlinear mixed models procedure of SAS 9.1 (SAS Institute, Inc.; see Wolfinger, 1999).

For the analysis of response latencies, all trials were excluded in which subjects gave no response, the subject indicated that the answer was wrong, or the reaction time was below $150 \mathrm{~ms}$ or $3 S D$ s distant from the individual mean. Reaction times were analysed in two ways: first, depending on the stimulus-type presented (stimulus-dependent analysis) and second, depending on the subject's response (classification of a stimulus as either angry, happy, sad, or neutral: response-dependent analysis). In the stimulusdependent analysis of RT, an ANCOVA with between factor Group, repeated measures factors Emotion and Picture, and the individual responses to the neutral face as a covariate was calculated. In the response-dependent analysis of RT, an ANOVA with between factor Group and repeated measures factor Classification (angry, happy, sad, neutral) was calculated.

P1, P2, and N170 amplitudes were analysed depending on subjects' emotional classifications. P1 and P2 amplitudes were analysed by an ANOVA with between factor Group and repeated measures factors 
Classification and Laterality (left, central, right). N170 amplitudes were analysed by an ANOVA with between factor Group and repeated measure factors Classification and Laterality (left, right).

\section{RESULTS}

\section{Valence and arousal ratings}

For the neutral face, mean valence rating was $M=5.27, S E=0.11$, and mean arousal rating was $M=3.16, S E=0.20$. Valence and arousal ratings of the neutral face were included in ANCOVAs for valence and arousal ratings of other faces, respectively. Adjusted mean valence and arousal ratings are illustrated in Figure 2.

The ANCOVA with the valence of the neutral face as a covariate showed a significant covariate effect on valence, $F(1,630)=27.57, p<.0001$. Furthermore, there was a main effect of Emotion, $F(2,84)=154.24, p<$ .0001 . Happy faces were rated as more pleasant than angry faces, $p<.0001$, or sad faces, $p<.0001$, and sad faces were rated more pleasant than angry faces, $p=.05$. The interaction Emotion $\times$ Picture, $F(10,630)=8.35, p<$ .0001 , showed that as the emotionality of the faces became more pronounced, happy faces were rated as increasingly more pleasant, whereas angry and sad faces were rated as increasingly more unpleasant (see Figure 2), linear regressions with numerical Pictures for each emotion: Valence $_{\text {Happy }}=4.7+0.12 \times$ Picture, slope $p=.003 ;$ Valence $_{\text {Angry }}=3.7-$ $0.19 \times$ Picture, slope $p<.0001$, and Valence Sad $=3.8-0.13 \times$ Picture, slope $p<.0001$. Neither a main effect of Group, $F(2,41)=2.30, p=.11$, nor a significant interaction with Group, Group $\times$ Emotion, $F(4,84)=0.72, p=$ .58 , Group $\times$ Picture, $F(10,630)=0.41, p=.94$, Group $\times$ Emotion $\times$ Picture, $F(20,630)=1.38, p=.12$, were observed for valence ratings.

The ANCOVA with the arousal of the neutral face as a covariate showed an effect of Neutral Face on arousal, $F(1,630)=157.76, p<.0001$. In addition, a main effect of Emotion, $F(2,84)=29.97, p<.0001$, was observed. Angry and sad faces were rated as more arousing than happy faces, both $p s<.0001$. In addition, angry faces were rated as more arousing than sad faces, $p=.005$. The interaction Emotion $\times$ Picture, $F(10,630)=$ $3.58, p=.0001$, showed that angry and sad faces were rated as increasingly more arousing as the emotionality of the pictures increased, linear regressions with numerical pictures: Arousal $_{\text {Angry }}=2.6+0.19 \times$ Picture, slope $p=.004 ;$ Arousal $_{\text {Sad }}=2.4+0.12 \times$ Picture, slope $p=.04$. On the other hand, the arousal ratings of happy faces did not change with increasing emotionality of the happy faces, slope $p=.62$. Furthermore, the interaction Group $\times$ Emotion, $F(4,84)=3.09, p=.02$, showed that individuals with social phobia and spider phobia rated angry faces as more arousing than 

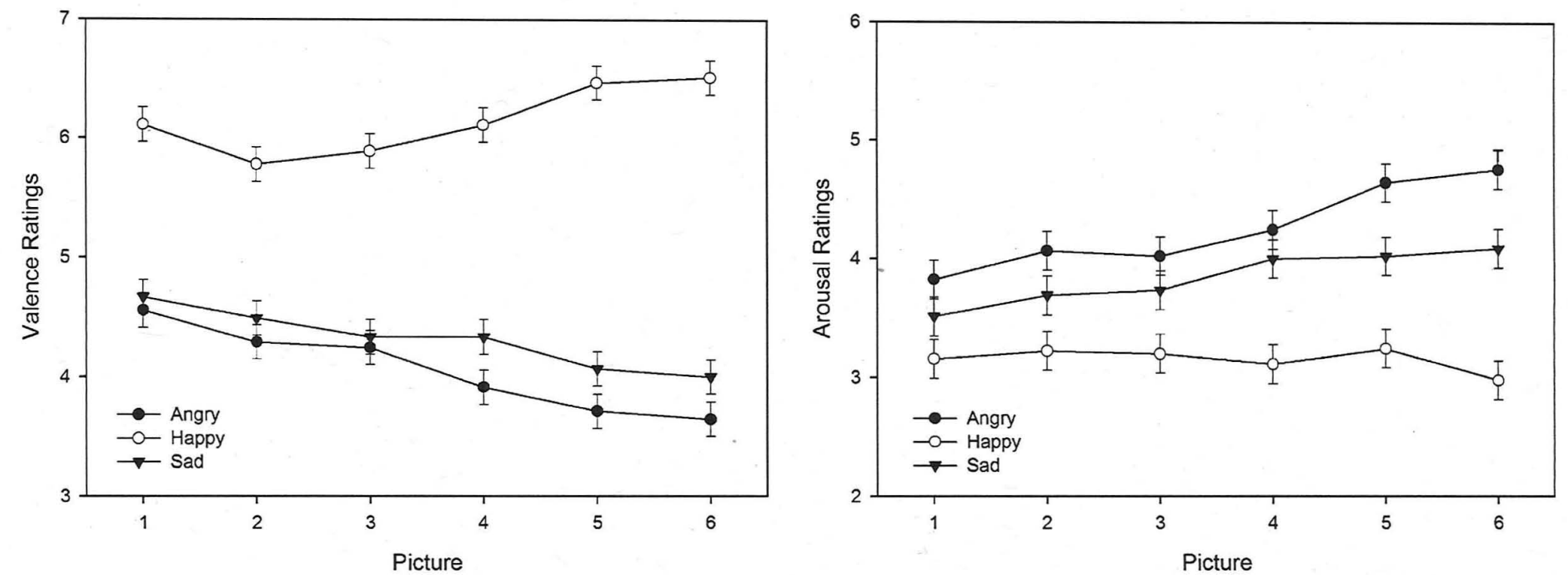

Figure 2. Adjusted mean valence and arousal ratings and $S E$ for each picture in the three emotional series. Means are adjusted for the rating of the neutral face as a covariate. The SAM scale (Bradley \& Lang, 1994; Lang, 1980) ranges from 1 to 9 with $1=$ highly unpleasant/low arousing and $9=$ highly pleasant/highly arousing. For the neutral face, mean valence rating was $M=5.27, S E=0.11$, and mean arousal rating was $M=3.16, S E=0.20$. 
controls, $p=.02$ and $p=.03$, respectively. However, the interaction Group $\times$ Emotion $\times$ Picture, $F(20,630)=1.26, p=.20$, was not significant.

\section{Emotional classifications}

Individuals with social phobia did not show a different latent trait to classify stimuli in the happy, $\alpha=-2.95, p=.25$, angry, $\alpha=-.16, p=.77$, or sad, $\alpha=-2.31, p=.15$, face series as angry compared to controls. As can be seen in Figure 3, there was no abrupt change in classifications from neutral to emotional, but rather a continuous move. Angry faces were frequently misclassified as sad by all groups, whereas sad and happy faces were more unambiguously classified as the correct emotion. Spider phobics showed a larger latent trait to classify even less pronounced happy faces in the happy face series as happy, $\alpha=.97, p=.02$. Although Figure 3 suggests a similar tendency for sad and angry faces, no such effect was significant, sad, $\alpha=.51$, $p=.26$, angry, $\alpha=.49, p=.39$.

\section{Reaction times}

Overall, subjects made mistakes (omissions and self-reported incorrect choices) in $5.0 \%$ of all trials. Groups did not differ with respect to mistakes, Kruskal-Wallis $\chi^{2}(2, N=45)=2.81, p=.25$.

Response-dependent analysis. A main effect of Classification, $F(3$, $126)=18.09, p<.0001$, was observed. Faces were identified fastest as happy followed by neutral, angry, and sad faces (see Figure 4). Contrasts revealed that happy faces were identified faster than angry, $p<.0001$, and sad faces, $p<.0001$. Furthermore, neutral faces were also identified faster than angry, $p=.006$, and sad faces, $p<.0001$, whereas the difference happy vs. neutral, $p=.08$, was not significant, and angry vs. sad, $p=.03$, was not significant after $\alpha$-adjustment. Although there was a tendency for individuals with spider phobia to respond faster than controls and those with social phobia, the main effect of Group failed significance, $F(2,42)=1.96, p=.15$.

Stimulus-dependent analysis. A main effect of Group, $F(2,42)=5.85$, $p=.006$, showed that spider phobic subjects responded generally faster than controls, $p=.03$, and social phobic subjects, $p=.002$. A main effect of Picture, $F(5,207)=4.97, p=.0003$, showed that the more unequivocal the stimuli, the faster all groups identified emotions, i.e., reaction times fell monotonically. A trend for a main effect of Emotion, $F(2,83)=2.92, p=.06$, and a significant interaction of Emotion $\times$ Picture, $F(10,416)=9.11, p<$ .0001 , were observed. Whereas happy and sad pictures were identified increasingly faster the more emotional the faces became, the response 

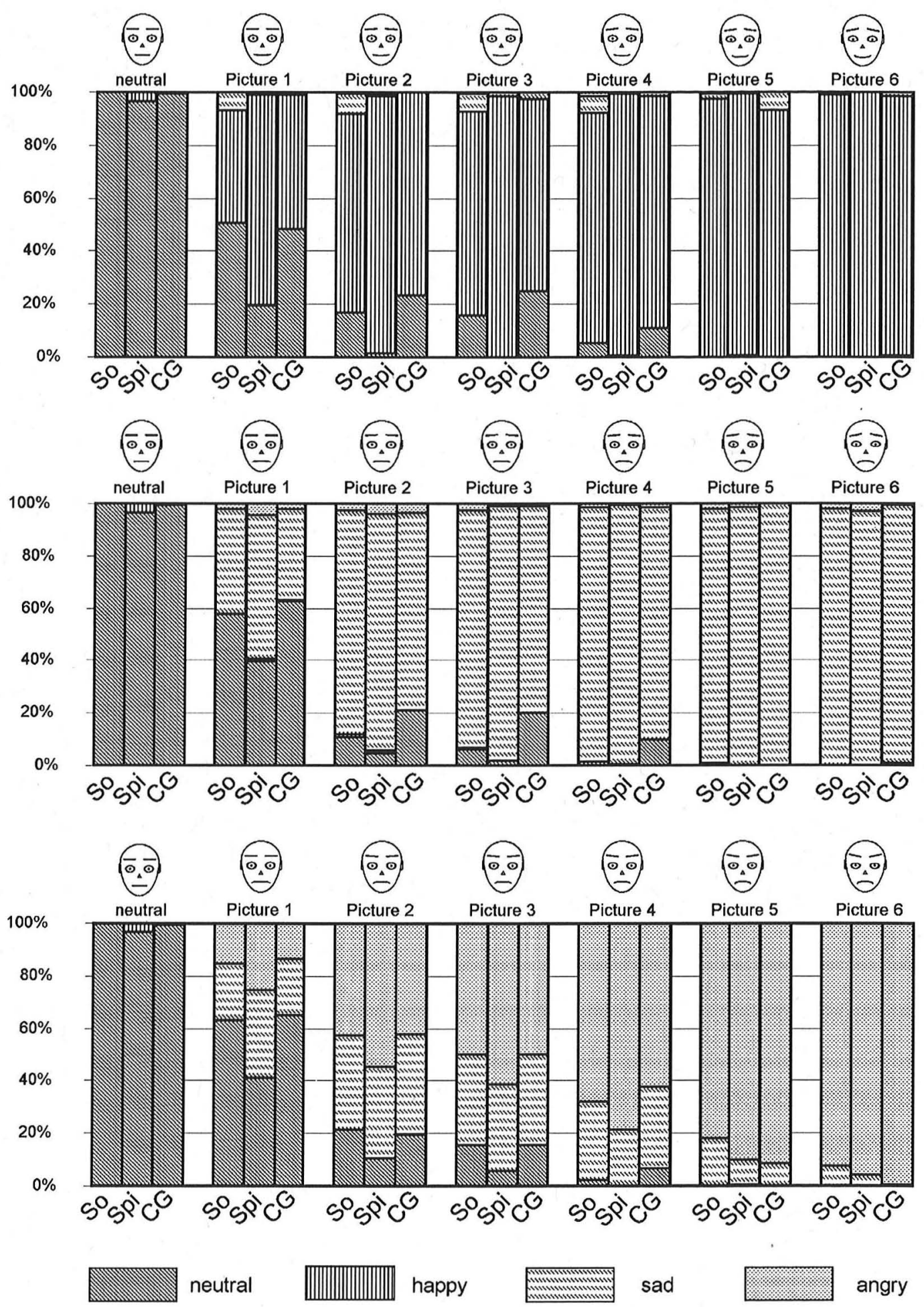

Figure 3. Classification frequencies as neutral, happy, sad, or angry for controls (CG), social phobics (So), and spider phobics (Spi) for the 3 emotional series: happy (upper row), sad (middle row), angry (bottom row) faces. 


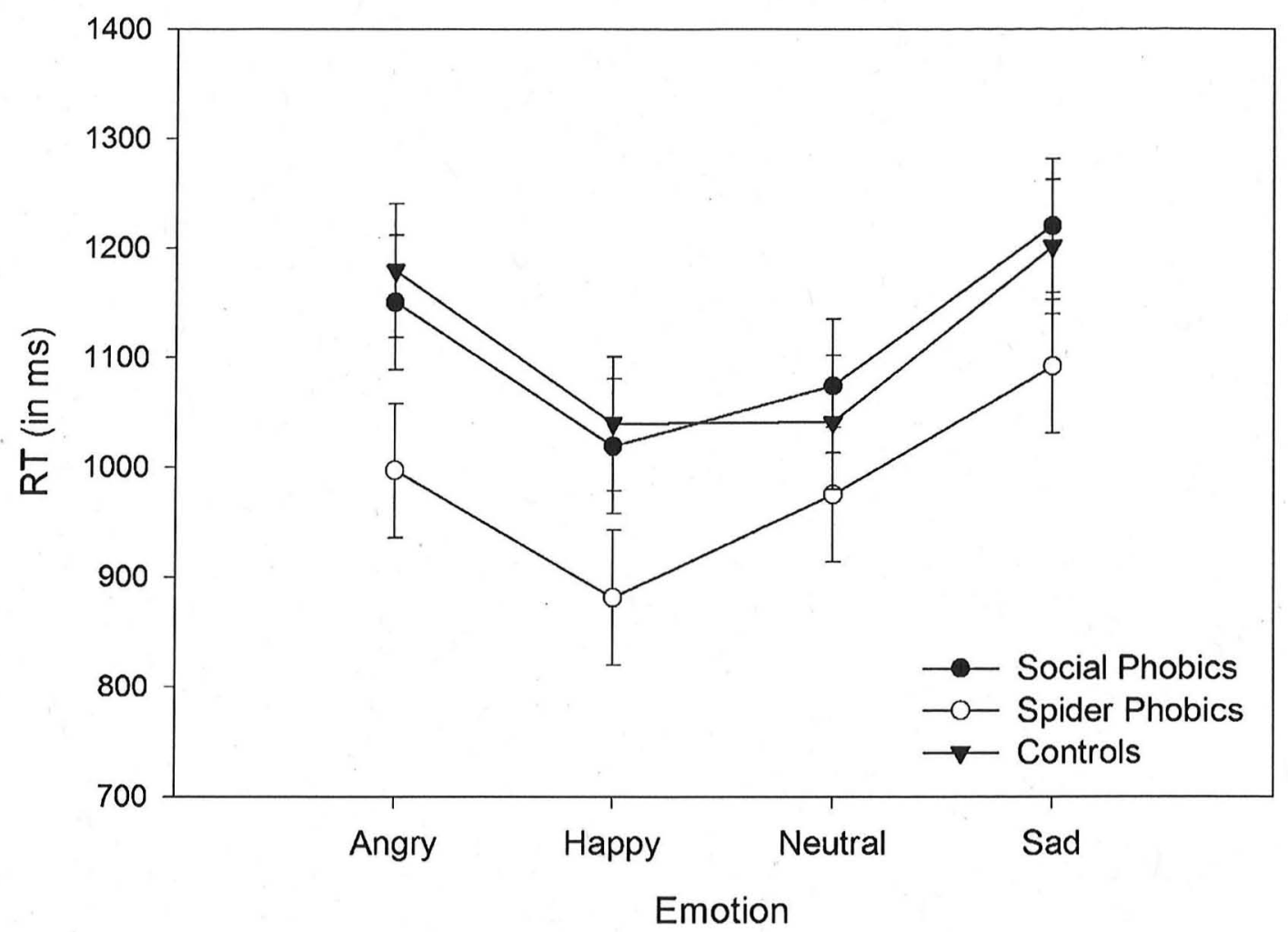

Figure 4. Response-dependent analysis: Adjusted mean response latencies (in ms) and $S E$ for each emotional classification category and each group.

latency of angry faces increased from picture 1 to 2 and decreased afterwards. Happy faces were classified generally faster than angry and sad faces, $p=.05$. Finally, the influence of the neutral face as a covariate was significant, $F(5,416)=8.04, p<.0001$, whereas the interactions Group $\times$ Emotion, $F(4,83)=0.93, p=.45$, Group $\times$ Picture, $F(10,207)=1.77, p=$ .07 , and Group $\times$ Emotion $\times$ Picture were not significant, $F(20,416)=1.12$, $p=.32$ (compare Figure 5).

\section{Analysis of $\mathrm{P} 1$}

The ANOVA revealed a main effect of Group, $F(2,39)=5.9, p=.006$, and a main effect of Laterality, $F(2,78)=15.86, p<.0001$. Subsequent contrasts showed that social phobic and spider phobic individuals exhibited larger P1 amplitudes than controls, $p=.002$ and $p=.01$, respectively (compare Figure 6). Furthermore, larger P1 amplitudes were observed over left and right compared to central sites, both $p \mathrm{~s}<.001$, and $\mathrm{P} 1$ was larger over the left compared to the right hemisphere, $p=.03$. There were no main effects or interactions with Classification. 
Stimulus-dependent analysis
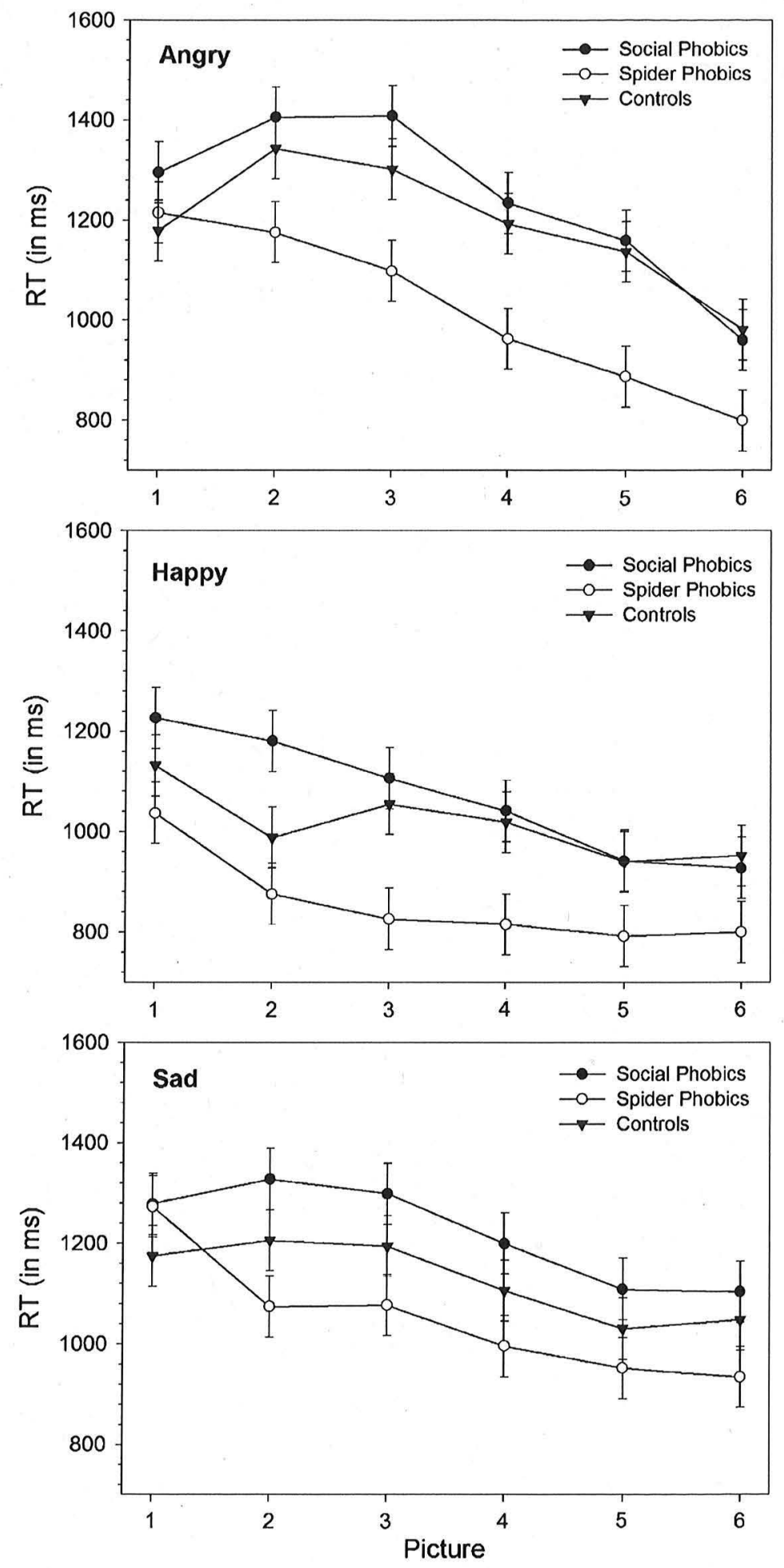

Figure 5. Stimulus-dependent analysis: Adjusted mean response latencies (in ms) and $S E$ for each group and each picture in the three emotional series (angry: upper row, happy: middle row, sad: bottom row). 


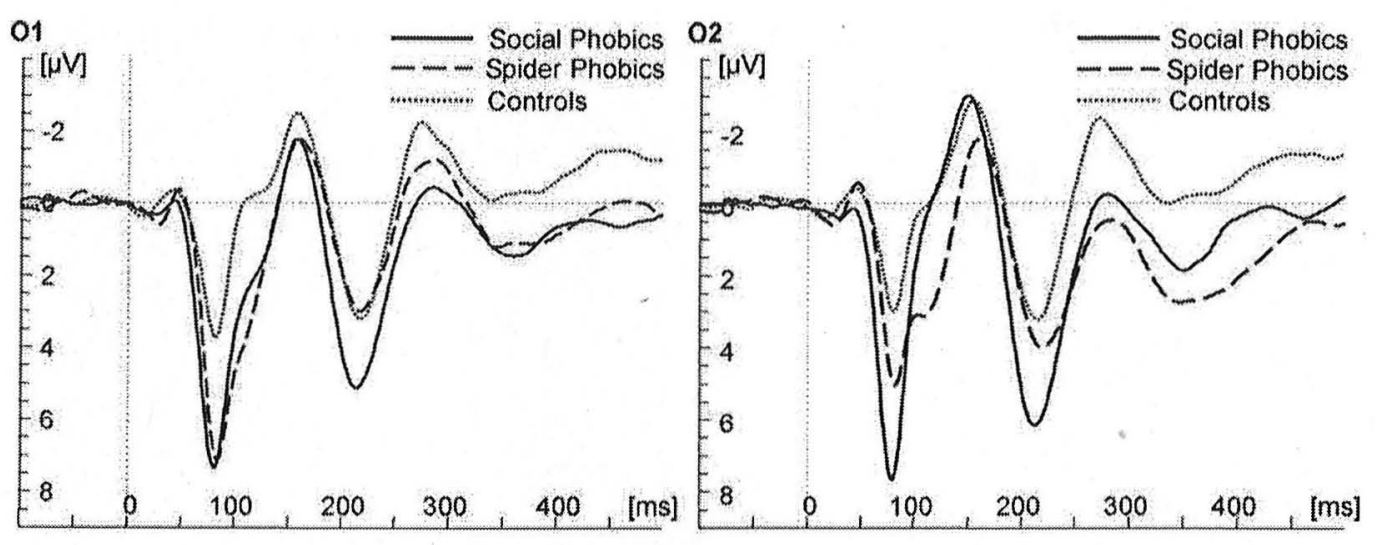

P1

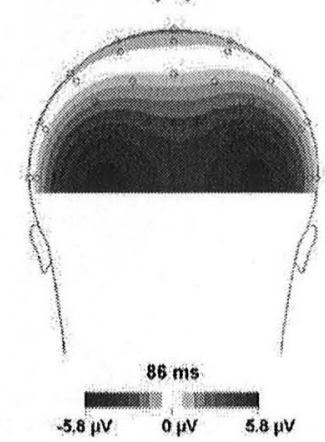

Figure 6. Grand average ERPs on electrode $\mathrm{O} 1$ (upper left) and $\mathrm{O} 2$ (upper right) for individuals with social phobia, spider phobia, and non-phobic controls. Map of the spatial distribution of the P1 taken from the grand average ERP with pooled data from $\mathrm{O} 1, \mathrm{Oz}$, and $\mathrm{O} 2$.

Because the enhanced P1 amplitude in both phobic groups suggested that P1 amplitude is related to phobia or increased anxiety in general and should thus covary with measures of general anxiety such as the FSS and/or the trait version of the STAI-T, separate ANCOVAs for each group with FSS and STAI-T scores as a covariate were calculated. In the social phobic group there was a significant relation between the individual score on the FSS and the magnitude of the $\mathrm{P} 1, F(1,78)=8.85, p=.004$, P1 amplitude $=1.43+$ $0.07 \times \mathrm{FSS}$, whereas this relation failed significance in the spider phobic group, $F(1,78)=2.26, p=.14$, and was not present in the control group, $F(1$, $72)=0.14, p=.71$. When interpreting this finding, one has to consider that anxiety-related psychopathology as indicated by the FSS was generally larger in spider phobics than controls, $p=.02$, and in social phobic than spider phobic individuals, $p=.003$ (comparison social phobic vs. control group, $p<.0005)$. There was no significant relationship between P1 amplitude and STAI-T, controls, $F(1,78)=2.33, p=.13$, social phobics, $F(1,78)=0.002, p=.96$, spider phobics, $F(1,78)=1.72, p=.19$. 


\section{Analysis of N170}

The ANOVA showed a main effect of Classification, $F(3,117)=23.18, p<$ .0001 . Contrasts showed larger N170 amplitudes for angry than for neutral, $p<.0001$, happy, $p<.0001$, or sad faces, $p=.001$. In addition, larger N170 amplitudes were observed for sad than for neutral, $p<.0001$, and for happy than for neutral faces, $p=.0006$ (compare Figure 7). The interaction Classification $\times$ Laterality, $F(3,123)=2.73, \quad p=.05$, revealed that the modulation of the N170 amplitude by perceived emotion was more pronounced over the right than the left hemisphere. Over the right hemisphere, angry faces elicited larger N170 amplitudes than happy faces, $p<.0001$, sad faces, $p=.0005$, or neutral faces, $p<.0001$, sad faces elicited larger N170 amplitudes than neutral faces, $p=.0005$, and happy faces larger N170 amplitudes than neutral faces, $p<.0001$. Over the left hemisphere a similar pattern was observed: angry faces elicited larger N170 amplitudes than happy, $p=.007$, and than neutral faces, $p<.0001$, and sad faces elicited larger N170 amplitudes than neutral faces, $p=.002$, whereas the contrast angry vs. sad, $p=.08$, was not significant and the contrast happy vs. neutral,
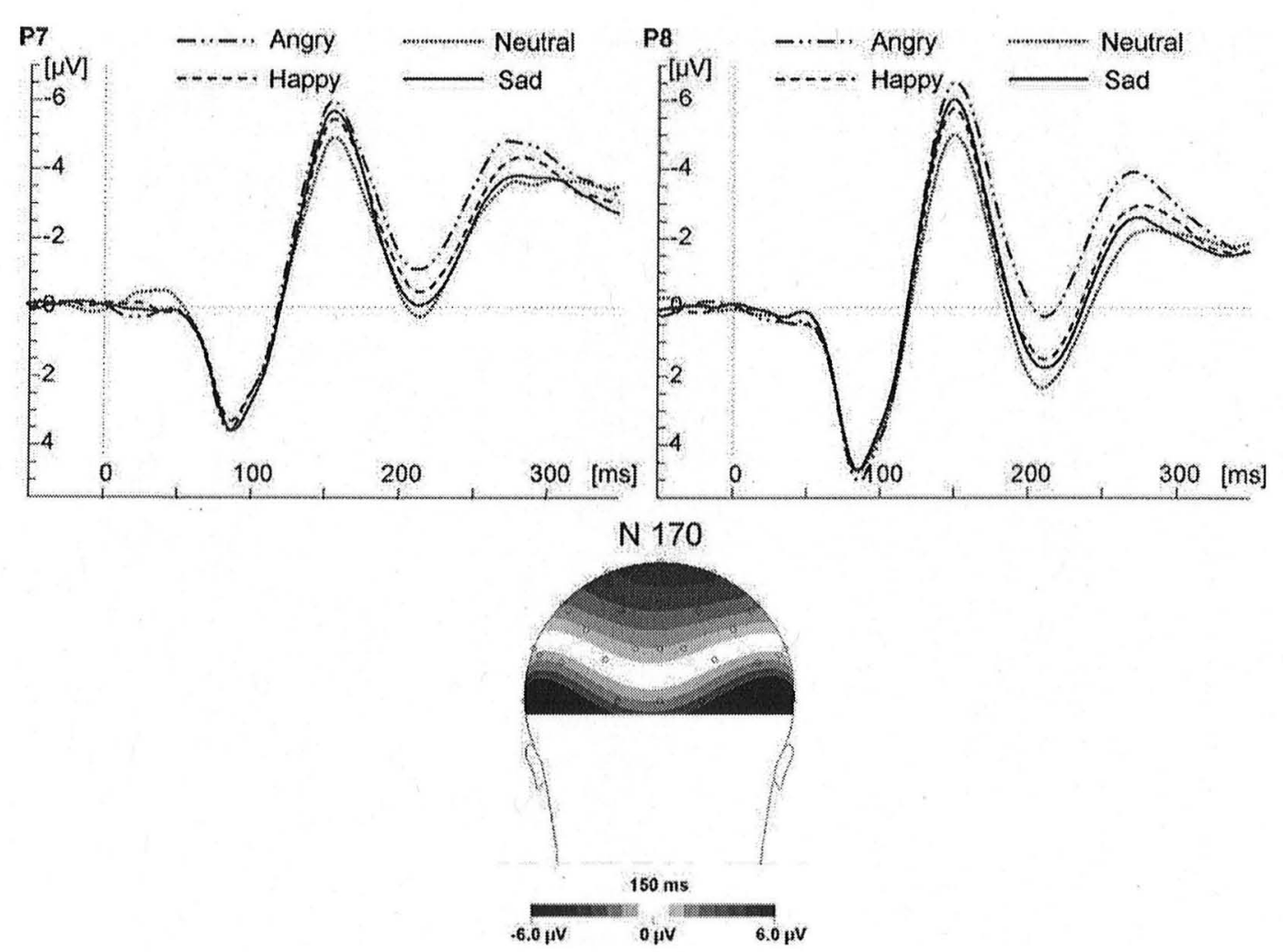

Figure 7. Grand average ERPs on electrode P7 (upper left) and P8 (upper right) for angry, happy, neutral, and sad faces. Map of the spatial distribution of the N170 taken from the grand average ERP with pooled data from P7 and P8. 
$p=.04$, failed significance after $\alpha$-adjustment. There were no main effects or interactions with Group.

\section{Analysis of P2}

The ANOVA showed main effects of Classification, $F(3,117)=6.41, p=$ .0005 , and Laterality, $F(2,78)=14.35, p<.0001$, as well as an interaction of Classification $\times$ Laterality, $F(6,234)=2.30, p=.04$. Neutrally classified faces elicited largest amplitudes $(M=4.9 \mu \mathrm{V}, S E=0.65 \mu \mathrm{V})$, followed by sad $(M=4.8 \mu \mathrm{V}, S E=0.65 \mu \mathrm{V})$ and happy $(M=4.4 \mu \mathrm{V}, S E=0.65 \mu \mathrm{V})$ classifications, while lowest $\mathrm{P} 2$ amplitudes were observed for the classification of faces as angry $(M=3.9 \mu \mathrm{V}, S E=0.65 \mu \mathrm{V})$. Pairwise comparisons for the main effect of Classification revealed that only the differences angryneutral, $p=.0001$, and angry-sad, $p=.0007$, remained significant, while the other comparisons failed significance after $\alpha$-adjustment or were not significant. Larger $\mathrm{P} 2$ amplitudes over lateral $(\mathrm{O} 1$ and $\mathrm{O} 2)$ compared to central $(\mathrm{Oz})$ electrodes were found, $p=.001$ and $p<.0001$, respectively. A trend for larger P2 amplitudes over the right compared to the left hemisphere was present, although it failed significance, $p=.06$. However, the interaction Classification $\times$ Laterality revealed that the classification of faces as happy elicited larger $\mathrm{P} 2$ amplitudes over right compared to left sites, $p=.01$, whereas the other comparisons failed significance after $\alpha$-adjustment (neutral), or were not significant (sad, angry).

No main effect of Group, $F(2,39)=1.32, p=.27$, interaction of Group $\times$ Classification, $F(6,117)=0.55, p=.77$, or Group $\times$ Classification $\times$ Laterality, $F(12,234)=1.35, p=.29$, was observed.

\section{DISCUSSION}

\section{Hypervigilance in phobia}

This study found larger early visual P1 amplitudes in phobic than in nonphobic subjects when processing schematic faces, regardless of the perceived emotion of faces. It has been suggested that the P1 reflects rapid global encoding processes of facial stimuli (Batty \& Taylor, 2003; Halit, de Haan, \& Johnson, 2000; Itier \& Taylor, 2002), which nevertheless start to differentiate among different emotional expressions (Batty \& Taylor, 2003; Kolassa \& Miltner, 2006; Pourtois et al., 2004, 2005a, 2005b). However, the role of the P1 in face processing is currently not well understood: Since the P1 is smaller for negative (contrast reversed) than inverted or upright faces (Itier \& Taylor, 2002), and larger for unattractive and atypical faces compared with attractive and typical faces (Halit et al., 2000), it has been ascribed a role in global face processing; on the other hand it is also influenced by emotion 
(Batty \& Taylor, 2003; Kolassa \& Miltner, 2006; Pourtois et al., 2004, 2005a, 2005b) as well as by attention (see Hillyard, Vogel, \& Luck, 1998, for a review).

The present results, demonstrating larger early visual P1 amplitudes in phobic than non-phobic subjects, are consistent with previous work positing a general hypervigilance in phobic patients (Eysenck, 1991, 1992, 1997). Our observation extends this previous work by indicating that the behavioural hypervigilance is accompanied by a "cortical hypervigilance". Correspondingly, the P1 amplitude has been found to be affected by attention, and it has been suggested that it reflects an attentional mechanism of early sensory gain control or amplification (see Hillyard et al., 1998, for a review). Hillyard et al. (1998) suggested that the P1 attention effect reflects a suppression of processing at unattended locations in order to reduce interference between attended and unattended information. It is thus possible that the attentional modulation of P1 might be the basis of the cortical hypervigilance observed in phobic compared to control subjects in the present study.

This cortical hypervigilance is further substantiated by the significant positive relationship between FSS scores and the magnitude of the P1 in the social phobic group. A similar trend was present in the specific phobia group, but failed significance. However, the general anxiety-related psychopathology as measured by the FSS spanned a larger range in the social phobic than in the spider phobic group, which may explain why the relationship was only observed in the social phobic group.

In addition, social and animal phobic subjects rated threatening angry faces as more arousing than non-phobic control subjects, supporting an increased behavioural hypervigilance in phobics. Furthermore, at least for happy faces, spider phobics also classified facial emotions generally faster and exhibited a greater latent trait to classify an emotional face as emotional than non-phobics. The lack of similarly faster responses of social phobics may be due to increased depression and general anxiety-related psychopathology in this patient group, which reciprocally diminishes fear reactivity.

Increasing psychopathology along the anxiety disorder spectrum (specific phobia $\rightarrow$ social phobia $\rightarrow$ panic disorder with agoraphobia $\rightarrow$ generalised anxiety disorder) is a well-established finding (Brown, Campbell, Lehman, Grisham, \& Mancill, 2001; Cuthbert et al., 2003; Lang, McTeague, \& Cuthbert, 2006). Lang (1985) suggested that fearfulness, defined as exaggerated defence reactions to specific cues in the environment, varies across the diagnostic spectrum of anxiety disorders from specific phobia over social phobia and panic disorder with agoraphobia to generalised anxiety disorder. Thus, while persons with panic disorder and generalised anxiety disorder are persistently distressed and apprehensive, they para- 
doxically appear to be less physiologically fearful, and an inverse relationship between physiological reactivity and self-reported symptomatic distress, negative affect and the frequency of mood-disorder comorbidity across the anxiety disorder spectrum has been observed. Even within social phobia, physiological reactivity decreases as negative affect increases (see Lang et al., 2006, for a review of supporting evidence). Lang et al. (2006) showed that individuals suffering from specific phobia are most reactive to specific cues in the environment, e.g., their startle reflex was most pronounced in a startle probe modulation task involving imagery of social and survival threat. However, defensive reflexes were diminished with increasing generalised anxiety and depression. It has been shown that this reflex pattern is not specific to fear cues that are related to phobics' clinical problems (Cook, Melamed, Cuthbert, McNeil, \& Lang, 1988; Cuthbert et al., 2003). Lang et al. (2006) suggested that generalised anxiety and comorbid depression additively attenuate startle potentiation to imagined threat in anxietydisordered patients.

\section{No threat advantage for angry faces in social phobia}

Individuals with social phobia showed neither faster responses to angry faces, nor a larger latent trait to classify a face as angry. Furthermore, social phobic persons did not differ from the control groups in their N170 amplitude to emotional schematic faces in general or angry schematic faces in particular. These observations strongly argue against an abnormal processing of angry schematic faces in social phobia. In accordance with these data, previous emotional Stroop studies also observed no attentional bias in social phobics when subjects were processing angry faces, which would have been reflected in prolonged response latencies when colournaming schematic angry faces or when identifying the gender of a photographic angry face (Kolassa et al., 2007; Kolassa \& Miltner, 2006).

Furthermore, the faster detection of happy faces than angry or sad faces agrees with the well-known faster identification of happy faces in choicereaction time tasks. Indeed, several studies reported faster categorisation of happy faces than of angry expressions (Billings, Harrison, \& Alden, 1993; Harrison, Gorelczenko, \& Cook, 1990; Hugdahl, Iversen, \& Johnsen, 1993; Kaufmann \& Schweinberger, 2004; Leppänen, Tenhunen, \& Hietanen, 2003), disgust (Leppänen et al., 2003; Stalans \& Wedding, 1985), sadness (Kirita \& Endo, 1995; Stanners, Byrd, \& Gabriel, 1985) or emotionally neutral faces (Hugdahl et al., 1993; Schweinberger, Baird, Blümler, Kaufmann, \& Mohr, 2003).

The present study is the first to investigate the influence of ambiguity in schematic faces on processing in social phobia. As such, we did not have measures of ambiguity available apart from misclassifications by partici- 
pants. Thus, the finding that classification was faster for happy faces may just show that the happy faces were less ambiguous than the sad and angry faces, or that they were easier to distinguish from the other two categories. As long as no separate measures of ambiguity are available, it is difficult to draw inferences from this result, even in the presence of the evidence for a "happy face advantage" as detailed above.

\section{Emotional modulation of the N170}

Consistent with previous studies (Blau et al., 2007; Caharel et al., 2005; Kolassa et al., 2007; Kolassa \& Miltner, 2006), this study found a modulation of the N170 by facial emotion, with larger N170 amplitudes for angry than for happy, sad, or neutral faces, and larger N170 amplitudes for happy or sad than for neutral faces. Presumably, such an emotional modulation of the N170 is only present when the identification of the facial emotion is explicitly task relevant, which might explain why some studies did not observe such an effect (Eimer \& Holmes, 2002; Holmes, Vuilleumier, \& Eimer, 2003; Schupp et al., 2004).

Although an emotional modulation of the N170 has been repeatedly observed, it remains unclear which task or stimulus properties influence the amplitude of the N170 in response to different facial expressions. Most of the studies mentioned above vary markedly with respect to this issue: The present findings replicate and extend results of an earlier study by our group (Kolassa et al., 2007), where largest N170 amplitudes were found in response to angry faces and smallest in response to neutral faces, with amplitudes to happy faces in between these two, when phobic subjects were requested to classify the emotional valence of schematic faces. However, Kolassa and Miltner (2006) found larger N170 amplitudes in response to happy compared to angry or neutral faces when using photographic face images in a similar design. Complicating things even more, Caharel et al. (2005) reported larger N170 amplitudes for emotional expressions of disgust than for neutral or smiling faces, while others (Batty \& Taylor, 2003; Blau et al., 2007) reported larger N170 for fearful compared to neutral facial expression. Thus, the identification of variables to explain the divergent results remains an open question, and our best hypothesis is that task is a crucial factormost importantly, explicit vs. implicit attention to the emotional content of the stimulus as well as differences between photographic and schematic stimuli seem to be a major influence on N170 modulation.

Finally, the present study did not replicate deviations of the N170 when social phobics process emotional faces, as was found by Kolassa and Miltner (2006) with photographic face images, but not by Kolassa et al. (2007) with 
schematic face stimuli. The hypothesis that this is due to the schematic face stimuli used appears warranted, but remains to be carefully investigated by future studies.

\section{Emotional modulation of the P2}

In contrast to the P1 and N170 component, the P2 component has been less frequently investigated in studies on electrophysiological correlates of facial processing. Latinus and Taylor (2005) suggested that the P2 may reflect a neurophysiological correlate of learning. They suggested that a high certainty of perception is associated with less deep processing of the stimulus, leading to lower P2 amplitudes. In contrast, less certainty of perception (as in the case of the neutral faces) would be associated with larger P2 amplitudes.

This study found a modulation of the P2 amplitude depending on the emotional perception of facial expressions as angry, happy, sad, or neutral. The largest amplitudes were observed for classifications of faces as neutral, followed by facial classifications as sad and happy, while lowest P2 amplitudes were observed for the classification of faces as angry. The classification of neutral faces may have been associated with less certainty than the classification of happy, sad or angry faces. However, this interpretation is speculative and further studies need to be conducted on the role of the $\mathrm{P} 2$ in facial processing.

In a study with non-face stimuli, larger P2 amplitudes were observed for negative-arousing and lowest P2 amplitudes for positive-arousing stimuli (Carretié, Martín-Loeches, Hinojosa, \& Mercado, 2001). The present study does not suggest a role of arousal as an influencing factor on P2 amplitudes. However, because both studies used different tasks and different stimuli (faces vs. non-faces) the comparability of results is limited.

\section{Conclusion}

To our knowledge, this study is the first to analyse the processing of morphed emotional schematic faces in non-phobic controls and individuals with social phobia. It shows that social phobic individuals show neither a larger latent trait to classify neutral or sad faces as angry nor a larger latent trait to classify angry faces earlier in the emotional continuum as angry. Second, this study found that the classification of stimuli as angry, sad or happy does not switch abruptly once some "ambiguity threshold" is reached-rather, classification probabilities move slowly and continuously as faces are morphed. Third, a generally larger excitability of the visual cortex was observed in phobic individuals as compared to non-phobic controls when processing schematic face stimuli, suggesting different attentional allocation processes in phobic persons in general compared to 
controls, which is consistent with an enhanced hypervigilance in the anxiety disorder spectrum.

Manuscript received 3 January 2006

Revised manuscript received 15 January 2007

Manuscript accepted 18 December 2007

First published online 2 April 2008

\section{REFERENCES}

Amaral, D. G., Price, J. L., Pitkanen, A., \& Carmichael, S. T. (1992). Anatomical organization of the primate amygdaloid complex. In J. Aggleton (Ed.), The amygdala: Neurobiological aspects of emotion, memory, and mental dysfunction (pp. 1-66). New York: Wiley.

American Psychiatric Association. (1994). Diagnostic and statistical manual of mental disorders (4th ed.). Washington, DC: Author.

Amir, N., Foa, E. B., \& Coles, M. E. (1998a). Automatic activation and strategic avoidance of threat-relevant information in social phobia. Journal of Abnormal Psychology, 107(2), 285290.

Amir, N., Foa, E. B., \& Coles, M. E. (1998b). Negative interpretation bias in social phobia. Behaviour Research and Therapy, 36(10), 945-957.

Averill, J. R. (1982). Anger and aggression: An essay on emotion. New York: Springer-Verlag.

Batty, M., \& Taylor, M. J. (2003). Early processing of the six basic facial emotional expressions. Brain Research: Cognitive Brain Research, 17(3), 613-620.

Becker, E. S., Rinck, M., Margraf, J., \& Roth, W. T. (2001). The emotional Stroop effect in anxiety disorders: General emotional or disorder specificity? Journal of Anxiety Disorders, 15(3), 147-159.

Bentin, S., Allison, T., Puce, A., Perez, E., \& McCarthy, G. (1996). Electrophysiological studies of face perception in humans. Journal of Cognitive Neuroscience, 8, 551-565.

Billings, L. S., Harrison, D. W., \& Alden, J. D. (1993). Age differences among women in the functional asymmetry for bias in facial affect perception. Bulletin of the Psychonomic Society, $31,317-320$.

Birbaumer, N., Grodd, W., Diedrich, O., Klose, U., Erb, M., Lotze, M., et al. (1998). fMRI reveals amygdala activation to human faces in social phobics. Neuroreport, 9(6), 1223-1226.

Blau, V. C., Maurer, U., Tottenham, N., \& McCandliss, B. D. (2007). The face-specific N170 component is modulated by emotional facial expression. Behavioral and Brain Functions, $3,7$.

Bradley, M. M., \& Lang, P. J. (1994). Measuring emotion: The Self-Assessment Manikin and the Semantic Differential. Journal of Behaviour Therapy and Experimental Psychiatry, 25(1), 4959.

Brown, T. A., Campbell, L. A., Lehman, C. L., Grisham, J. R., \& Mancill, R. B. (2001). Current and lifetime comorbidity of the DSM-IV anxiety and mood disorders in a large clinical sample. Journal of Abnormal Psychology, 110(4), 585-599.

Caharel, S., Courtay, N., Bernard, C., Lalonde, R., \& Rebai, M. (2005). Familiarity and emotional expression influence an early stage of face processing: An electrophysiological study. Brain and Cognition, 59(1), 96-100.

Carretié, L., Martín-Loeches, M., Hinojosa, J. A., \& Mercado, F. (2001). Emotion and attention interaction studied through event-related potentials. Journal of Cognitive Neuroscience, 13(8), 1109-1128. 
Chatrian, G. E., Lettich, E., \& Nelson, P. L. (1988). Modified nomenclature for the "10\%" electrode system. Journal of Clinical Neurophysiology, 5(2), 183-186.

Coles, M. E., \& Heimberg, R. G. (2005). Recognition bias for critical faces in social phobia: A replication and extension. Behaviour Research and Therapy, 43(1), 109-120.

Cook, E. W. 3rd, Melamed, B. G. Cuthbert, B. N. McNeil, D. W. \& Lang, P. J. (1988). Emotional imagery and the differential diagnosis of anxiety. Journal of Consulting and Clinical Psychology, 56(5), 734-740.

Cuthbert, B. N., Lang, P. J., Strauss, C., Drobes, D., Patrick, C. J., \& Bradley, M. M. (2003). The psychophysiology of anxiety disorder: Fear memory imagery. Psychophysiology, 40(3), 407422.

Eimer, M., \& Holmes, A. (2002). An ERP study on the time course of emotional face processing. Neuroreport, 13(4), 427-431.

Eysenck, M. W. (1991). Cognitive factors in clinical psychology: Potential relevance to therapy. In M. Briley \& S. E. File (Eds.), New concepts in anxiety. London: Macmillan.

Eysenck, M. W. (1992). Anxiety: The cognitive perspective. Hove, UK: Lawrence Erlbaum Associates, Ltd.

Eysenck, M. W. (1997). Anxiety and cognition: A unified theory. Hove, UK: Psychology Press.

Fydrich, T. (2002). Soziale Phobie und Angst Inventar. In E. Brähler, J. Schumacher, \& B. Strauß (Eds.), Diagnostische Verfahren in der Psychotherapie [Diagnostic methods in psychotherapy] (pp. 335-338). Göttingen, Germany: Hogrefe.

Gilboa-Schechtman, E., Foa, E. B., \& Amir, N. (1999). Attentional biases for facial expressions in social phobia. The Face-in-the-Crowd Paradigm. Cognition and Emotion, 13(3), 305-318.

Gratton, G., Coles, M. G. H., \& Donchin, E. (1983). A new method for off-line removal of ocular artifact. Electroencephalography and Clinical Neurophysiology, 55, 468-484.

Halit, H., de Haan, M., \& Johnson, M. H. (2000). Modulation of event-related potentials by prototypical and atypical faces. Neuroreport, 11(9), 1871-1875.

Harrison, D. W., Gorelczenko, P. M., \& Cook, J. (1990). Sex differences in the functional asymmetry for facial affect perception. The International Journal of Neuroscience, 52(1-2), $11-16$.

Hautzinger, M., Bailer, M., Worall, H., \& Keller, F. (2000). Becks-Depressions-Inventar (BDI) Testhandbuch (2nd ed.). Bern, Switzerland: Hans Huber.

Henson, R. N., Goshen-Gottstein, Y., Ganel, T., Otten, L. J., Quayle, A., \& Rugg, M. D. (2003). Electrophysiological and haemodynamic correlates of face perception, recognition and priming. Cerebral Cortex, 13(7), 793-805.

Hillyard, S. A., Vogel, E. K., \& Luck, S. J. (1998). Sensory gain control (amplification) as a mechanism of selective attention: Electrophysiological and neuroimaging evidence. Philosophical Transactions of the Royal Society London: Series B Biological Sciences, 353(1373), $1257-1270$.

Hinsch, R., \& Pfingsten, U. (2002). Gruppentraining sozialer Kompetenzen (GSK) [Group training of social skills] (4th ed.). Weinheim, Germany: Beltz.

Hirsch, C. R., \& Mathews, A. (2000). Impaired positive inferential bias in social phobia. Journal of Abnormal Psychology, 109(4), 705-712.

Holm, S. (1979). A simple sequentially rejective multiple test procedure. Scandinavian Journal of Statistics, 6, 65-70.

Holmes, A., Vuilleumier, P., \& Eimer, M. (2003). The processing of emotional facial expression is gated by spatial attention: Evidence from event-related brain potentials. Brain Research. Cognitive Brain Research, 16(2), 174-184.

Hope, D. A., Rapee, R. M., Heimberg, R. G., \& Dombeck, M. J. (1990). Representations of the self in social phobia: Vulnerability to social threat. Cognitive Therapy and Research, 21, 681696. 
Hugdahl, K., Iversen, P. M., \& Johnsen, B. H. (1993). Laterality for facial expressions: Does the sex of the subject interact with the sex of the stimulus face? Cortex, 29(2), 325-331.

Itier, R. J., \& Taylor, M. J. (2002). Inversion and contrast polarity reversal affect both encoding and recognition processes of unfamiliar faces: A repetition study using ERPs. NeuroImage, 15(2), 353-372.

Kaufmann, J. M., \& Schweinberger, S. R. (2004). Expression influences the recognition of familiar faces. Perception, 33(4), 399-408.

Kirita, T., \& Endo, M. (1995). Happy-face advantage in recognizing facial expressions. Acta Psychologia, 89, 149-163.

Klorman, R., Weerts, T. C., Hastings, J. E., Melamed, B. G., \& Lang, P. J. (1974). Psychometric description of some specific fear questionnaires. Behavior Therapy, 5, 401-409.

Kolassa, I. T., Kolassa, S., Musial, F., \& Miltner, W. H. R. (2007). Event-related potentials to schematic faces in social phobia. Cognition and Emotion, 21(8), 1721-1744.

Kolassa, I. T., \& Miltner, W. H. R. (2006). Do social phobics fear angry faces? Psychophysiological correlates of face processing. Brain Research, 1118(1), 130-141.

Kolassa, I. T., Musial, F., Kolassa, S., \& Miltner, W. H. R. (2006). Event-related potentials to threatening schematic stimuli in spider phobic and non-phobic subjects. BMC Psychiatry, 6, 38.

Laird, N. M., \& Ware, J. H. (1982). Random-effects models for longitudinal data. Biometrics, 38(4), 963-974.

Lang, P. J. (1980). Behavioral treatment and bio-behavioral assessment: Computer applications. In J. B. Sidowski, J. H. Johnson, \& T. A. Williams (Eds.), Technology in mental health care delivery systems. Norwood, NJ: Ablex Publishing.

Lang, P. J. (1985). The cognitive psychophysiology of emotion: Fear and anxiety. In A. H. Tuma \& J. D. Maser (Eds.), Anxiety and the anxiety disorders (Vol. 3, pp. 131-170). Hillsdale, NJ: Lawrence Erlbaum Associates, Inc.

Lang, P. J., McTeague, L. M., \& Cuthbert, B. N. (2006). Fear, anxiety, depression and the anxiety disorder spectrum: A psychophysiological analysis. In T. Baker, R. Bootzin, \& T. Treat (Eds.), Psychological clinical science: Recent advances in theory and practice. Integrative perspectives in honor of Richard M. McFall (pp. 167-195). Hillsdale, NJ: Lawrence Erlbaum Associates, Inc.

Latinus, M., \& Taylor, M. J. (2005). Holistic processing of faces: Learning effects with Mooney faces. Journal of Cognitive Neuroscience, 17(8), 1316-1327.

Laux, L. Glanzmann, P. Schaffner, P. \& Spielberger, C. D. (1981). Das State-Trait-Angstinventar (STAI-G) [C. D. Spielberger, R. L. Gorsuch, \& R. E. Lushene (1970). The State Trait Anxiety Inventory. Palo Alto, CA: Consulting Psychologists Press]. Weinheim, Germany: Beltz.

LeDoux, J. (1998). Fear and the brain: Where have we been, and where are we going? Biological Psychiatry, 44, 1229-1238.

Leppänen, J. M., Tenhunen, M., \& Hietanen, J. K. (2003). Faster choice-reaction times to positive than to negative facial expressions. Journal of Psychophysiology, 17(3), 113-123.

Luck, S. J., Woodman, G. F., \& Vogel, E. K. (2000). Event-related potential studies of attention. Trends in Cognitive Sciences, 4(11), 432-440.

Lundh, L. G., \& Öst, L. G. (1996). Recognition bias for critical faces in social phobics. Behaviour Research and Therapy, 34(10), 787-794.

Lundqvist, D., Esteves, F., \& Öhman, A. (1999). The face of wrath: Critical features for conveying facial threat. Cognition and Emotion, 13(6), 691-711.

Maidenberg, E., Chen, E., Craske, M., Bohn, P., \& Bystritsky, A. (1996). Specificity of attentional bias in panic disorder and social phobia. Journal of Anxiety Disorders, 10, 529541. 
Mangun, G. R. (1995). Neural mechanisms of visual selective attention. Psychophysiology, 32(1), 4-18.

Mansell, W., Ehlers, A., Clark, D. M., \& Chen, Y.-P. (2002). Attention to positive and negative social-evaluative words: Investigating the effects of social anxiety, trait anxiety and social threat. Anxiety, Stress and Coping, 15, 19-29.

Mattia, J. I., Heimberg, R. G., \& Hope, D. A. (1993). The revised Stroop color-naming task in social phobics. Behaviour Research and Therapy, 31(3), 305-313.

Öhman, A., Lundqvist, D., \& Esteves, F. (2001). The face in the crowd revisited: A threat advantage with schematic stimuli. Journal of Personality and Social Psychology, 80(3), 381396.

Oldfield, R. C. (1971). The assessment and analysis of handedness: The Edinburgh inventory. Neuropsychologia, 9(1), 97-113.

Öst, L. G. (1989). One-session treatment for specific phobias. Behaviour Research and Therapy, 27(1), 1-7.

Phan, K. L., Fitzgerald, D. A., Nathan, P. J., \& Tancer, M. E. (2006). Association between amygdala hyperactivity to harsh faces and severity of social anxiety in generalized social phobia. Biological Psychiatry, 59(5), 424-429.

Pishyar, R., Harris, L. M., \& Menzies, R. G. (2004). Attentional bias for word and faces in social anxiety. Anxiety. Stress and Coping, 17, 118-121.

Pizzagalli, D., Lehmann, D., Koenig, T., Regard, M., \& Pascual-Marqui, R. D. (2000). Faceelicited ERPs and affective attitude: Brain electric microstate and tomography analyses. Clinical Neurophysiology, 111(3), 521-531.

Pizzagalli, D., Regard, M., \& Lehmann, D. (1999). Rapid emotional face processing in the human right and left brain hemispheres: An ERP study. Neuroreport, 10(13), 2691-2698.

Pourtois, G., Dan, E. S., Grandjean, D., Sander, D., \& Vuilleumier, P. (2005a). Enhanced extrastriate visual response to bandpass spatial frequency filtered fearful faces: Time course and topographic evoked-potentials mapping. Human Brain Mapping, 26(1), 65-79.

Pourtois, G., Grandjean, D., Sander, D., \& Vuilleumier, P. (2004). Electrophysiological correlates of rapid spatial orienting towards fearful faces. Cerebral Cortex, 14(6), 619-633.

Pourtois, G., Thut, G., Grave de Peralta, R., Michel, C., \& Vuilleumier, P. (2005b). Two electrophysiological stages of spatial orienting towards fearful faces: Early temporo-parietal activation preceding gain control in extrastriate visual cortex. NeuroImage, 26(1), 149-163.

Schubö, A., Gendolla, G. H. E., Meinecke, C., \& Abele, A. E. (2006). Detecting emotional faces and features in a visual search paradigm: Are faces special? Emotion, 6(2), 246-256.

Schupp, H. T., Öhman, A., Junghöfer, M., Weike, A. I., Stockburger, J., \& Hamm, A. O. (2004). The facilitated processing of threatening faces: An ERP analysis. Emotion, 4(2), 189-200.

Schweinberger, S. R., Baird, L. M., Blümler, M., Kaufmann, J. M., \& Mohr, B. (2003). Interhemispheric co-operation for face recognition but not for affective facial expressions. Neuropsychologia, 41(4), 407-414.

Schweinberger, S. R., Pickering, E. C., Jentzsch, I., Burton, A. M., \& Kaufmann, J. M. (2002). Event-related brain potential evidence for a response of inferior temporal cortex to familiar face repetitions. Brain Research, Cognitive Brain Research, 14(3), 398-409.

Smith, N. K., Cacioppo, J. T., Larsen, J. T., \& Chartrand, T. L. (2003). May I have your attention, please: Electrocortical responses to positive and negative stimuli. Neuropsychologia, 41(2), 171-183.

Spector, I. P., Pecknold, J. C., \& Libman, E. (2003). Selective attentional bias related to the noticeability aspect of anxiety symptoms in generalized social phobia. Journal of Anxiety Disorders, 17(5), 517-531.

Stalans, L., \& Wedding, D. (1985). Superiority of the left hemisphere in the recognition of emotional faces. The International Journal of Neuroscience, 25(3-4), 219-223. 
Stanners, R. F., Byrd, D. M., \& Gabriel, R. (1985). The time it takes to identify facial expressions: Effect of age, gender of subject, sex of sender, and type of expressions. Journal of Nonverbal Behavior, 9, 201-213.

Stein, M. B., Goldin, P. R., Sareen, J., Zorrilla, L. T., \& Brown, G. G. (2002). Increased amygdala activation to angry and contemptuous faces in generalized social phobia. Archives of General Psychiatry, 59(11), 1027-1034.

Stopa, L., \& Clark, D. M. (2000). Social phobia and interpretation of social events. Behaviour Research and Therapy, 38(3), 273-283.

Straube, T., Kolassa, I. T., Glauer, M., Mentzel, H. J., \& Miltner, W. H. (2004). Effect of task conditions on brain responses to threatening faces in social phobics: An event-related functional magnetic resonance imaging study. Biological Psychiatry, 56(12), 921-930.

Straube, T., Mentzel, H. J., \& Miltner, W. H. (2005). Common and distinct brain activation to threat and safety signals in social phobia. Neuropsychobiology, 52(3), 163-168.

Turner, S. M., Beidel, D. C., Dancu, C. V., \& Stanley, M. A. (1989). An empirically derived inventory to measure social fears and anxiety: The Social Phobia and Anxiety Inventory. Psychological Assessment, 1, 35-40.

Veit, R., Flor, H., Erb, M., Hermann, C., Lotze, M., Grodd, W., et al. (2002). Brain circuits involved in emotional learning in antisocial behavior and social phobia in humans. Neuroscience Letters, 328(3), 233-236.

Wittchen, H.-U., Wunderlich, U., Gruschwitz, S., \& Zaudig, M. (1997). Strukturiertes Klinisches Interview für DSM-IV [Structured clinical interview for DSM-IV]. Göttingen, Germany: Hogrefe.

Wolfinger, R. D. (1999). Fitting nonlinear mixed models with the new NLMIXED procedure. Cary, NC: SAS Institute, Inc.

Wolpe, J., \& Lang, P. J. (1964). A fear survey schedule for use in behaviour therapy. Behaviour Research and Therapy, 159, 27-30. 